\title{
Clinicobacteriological study of chronic dacryocystitis in Egypt
}

\author{
Sahar Negm ${ }^{*}$, Amal Aboelnour ${ }^{2}$, Tarek Saleh ${ }^{3}$, Mohamed Yasser $^{4}$ and Olfat Hassanin ${ }^{4}$
}

\begin{abstract}
Background: Empirical antibiotic treatment is a common practice to manage chronic dacryocystitis in many healthcare settings in spite of the probability for changing in the types of microbial isolates.

The aims of this study were to find out the current clinicomicrobiological profile of adult cases with chronic dacryocystitis and to determine the antibiogram of the isolated organisms to the commonly prescribed antibiotics.

Results: Of the 25 samples obtained, 15 (60\%) yielded a positive culture, 12 (48\%) showed single bacterial isolate while 3 (12\%) had mixed (two types) bacterial isolates.

A total of 18 different strains of microorganisms were obtained from 25 cases, with 12/18 (66.7\%) Gram-positive, 5/18 (27.7\%) Gram-negative isolates, and 1/18 (5.5\%) was fungal isolate. Coagulase-negative staphylococci were the most frequently found Gram-positive bacteria (22.2\%), while Klebsiella species was the predominant of Gram-negative bacteria (16.6\%). The majority of the isolated bacterial strains were sensitive to gatifloxacin (88\%) and amikacin (88\%) while the main resistance of the bacterial isolates, recovered from chronic dacryocystitis, was to cephalexin (59\%).

Conclusion: There is a continuous possibility of changing the type of pathogens responsible for dacryocystitis as well as their susceptibility to antibiotics. Microbiological study with microbial culture and antibiotic sensitivity test has to be done to all cases of chronic dacryocystitis for a better choice of antibiotic prophylaxis and treatment options, and to guard against the emergence of more drug-resistant strains.
\end{abstract}

Keywords: Antibiotic susceptibility, Aminoglycosides, Nasolacrimal duct, Staphylococci

\section{Background}

Dacryocystitis is an infection of the nasolacrimal sac, frequently occurs because of obstruction of the nasolacrimal duct that can affect patients of any age (Bharathi et al. 2008). Obstruction of the nasolacrimal duct leads to stagnation of tears and mucous secretion in the lacrimal sac and the lacrimal drainage system which ends with dacryocystitis with clinical presentations include pain, redness, swelling over the inner side of the lower eyelid, and epiphora with or without purulent discharge (Bharathi et al. 2008). The etiology of nasolacrimal duct obstruction may be primary idiopathic stenosis (Mills et al. 2007), usually in elder female and middle age (Hartikainen et al. 1997). It may be secondary, related to a malformation of the tear duct, injury, eye infection, neoplasm, or trauma. However, simple stenosis

\footnotetext{
*Correspondence: saharnegm1@hotmail.com

'Department of Microbiology and Parasitology, Research Institute of

Ophthalmology, El Ahram Street, (RIO), Giza 12611, Egypt

Full list of author information is available at the end of the article
}

with epiphora may be tolerable by a large number of patients for many years (Hartikainen et al. 1997).

The chronic form of dacryocystitis is associated with chronic tearing, thickening of the lacrimal drainage system, and accumulation of germs, usually the majority of patients harbor multiple microorganisms. It is a constant threat to the cornea and orbital tissue. Complications of dacryocystitis include fistula, corneal ulcer, and orbital cellulitis; moreover, it causes social embarrassment due to long-lasting epiphora (Badhu et al. 2006; Mandal et al. 2008; Kebede et al. 2010; Huber-Spitzy et al. 1992; Das et al. 2008a; Chaudhry et al. 2005).

Although dacryocystitis is a common problem, there have been few studies on the adult lacrimal duct obstruction LDO, from a microbiological investigation point of view during the past 20 years. These studies demonstrated that, Staphylococcus epidermidis and Staphylococcus aureus are the most commonly isolated bacteria in lacrimal sac infections in the adult (Hartikainen et al. 1997). However, there is a probability for 
changing in the types of microbiological isolates in dacryocystitis. Some recent reports have indicated more common isolation of Gram-negative organisms, while other studies have noticed increased numbers of methicillin-resistant Staphylococcus aureus (MRSA) infections. This information could affect the treatment of dacryocystitis markedly (Mills et al. 2007). Staphylococcus aureus, Streptococcus pneumoniae, and Haemophilus influenzae have been found to be common pathogens in children, and S. epidermidis, S. aureus, S. pneumoniae, and Pseudomonas aeruginosa are the most frequent microorganisms in adults (Eslami et al. 2018).

This study aims to identify the microbial etiology and to demonstrate the antibiogram of microbial isolates to commonly used antibacterial agents, and to find out the current clinicobacteriological profile of chronic dacryocystitis in adults.

\section{Materials and methods}

A prospective study to 25 patients with chronic dacryocystitis who were submitted to external dacryocystorhinostomy (DCR) for treatment of nasolacrimal duct obstruction (NLDO) was carried out, and microbiological analyses to 25 lacrimal sac contents were done. The study was carried out during the period from March 2012 to March 2014, in the Research Institute of Ophthalmology (Microbiology and Immunology Unit together with Oculoplastic Unit), and had an agreement of the medical research committee.

\section{Patients}

Patients attending the oculoplastic clinic were first examined by an ophthalmologist, and dacryocystitis was clinically defined, examined, and diagnosed as chronic dacryocystitis, based on their history, signs, and symptoms; epiphora for long period, and presence of mucoid or mucopurulent material coming out on pressure over the sac area or during lacrimal drainage system irrigation. Patients presenting with tenderness, erythema, and swollen lacrimal sac area were excluded from the study; they were diagnosed as acute dacryocystitis.

\section{Inclusion criteria}

All patients who were submitted to external DCR for chronic dacryocystitis due to primary acquired NLDO.

\section{Exclusion criteria}

Cases younger than 20 years were not included in this study. All cases with a history of topical or systemic antibiotic administration 1 week ago before surgery and before sample collection were excluded. Acute dacryocystitis cases, cases with a past history of infection, inflammatory nasal or sinus disease, endonasal surgery, and maxillofacial surgery were excluded.
All patients diagnosed as dacryocystitis due to a cause other than primary acquired nasolacrimal duct obstruction through detection of obstruction on syringing and probing or on performing anteroposterior and lateral dacryocystography using lipiodol or detected with endonasal endoscope, canalicular obstruction; canalolithiasis; lacrimal system tumor; previous trauma to the ocular and nasal regions; bony deformity; abnormal intranasal anatomy, were excluded from the study in addition to advanced deviated nasal septum, middle turbinate (MT) hypertrophy, or concha bullosa, and nasal polyps.

All patients who had a history of any lacrimal operative procedures in the past were excluded from the study.

\section{Collection of samples}

Standard operating procedures were followed to all cases during sample collection. External-DCR were done under general anesthesia by two oculoplastic surgeons and material (lacrimal sac cultures) was obtained directly from the lacrimal sac content while making sac flap using sterile cotton wool swabs (so as to avoid the risk of sample contamination). Great care was taken to guard against any possible contamination of the specimens. It was sent promptly to the microbiology laboratory for immediate processing. The specimens were cultured and results were analyzed.

\section{Bacterial isolation and sensitivity test}

Inoculation of specimens was done following standard procedures (Cheesbrough 2006). The material of lacrimal sac content was inoculated directly onto the different media: blood agar, chocolate agar, MacConkey's agar, Sabouraud's dextrose agar, and brain heart infusion broth. The sample obtained was also used to make direct Gram's staining. The inoculated media were all incubated aerobically at $37 \mathrm{C}$ for $24 \mathrm{~h}$, examined daily, and finally declared as culture negative after 5 days if no organism had grown. Chocolate agar plates were incubated in $\mathrm{CO} 2$ to ensure $5-10 \% \mathrm{CO} 2$.

Significant microbial growth was considered when positive culture was obtained for the same organism in more than one type of solid media and, or there was heavy growth in one solid medium at the site of inoculation and, or if positive culture in one medium gave the same finding of direct film by microscopy. Positive growth culture was followed by bacterial identification according to colony morphology, Gram staining, pigments, and biochemical reactions. Antimicrobial susceptibility tests were applied to all bacterial isolates according to the standard disc diffusion method (Hudzicki 2013).

The following antibiotic disks were used: Gentamicin $(10 \mu \mathrm{g})$, Amikacin $(30 \mu \mathrm{g})$, Tobramycin $(30 \mu \mathrm{g})$, gatifloxacin 
$(5 \mu \mathrm{g})$, ciprofloxacin $(30 \mu \mathrm{g})$, levofloxacin $(5 \mu \mathrm{g})$, ceftazidime $(30 \mu \mathrm{g})$, cephalexin $(30 \mu \mathrm{g})$, cefotaxime $(30 \mu \mathrm{g})$, and chloramphenicol $(30 \mu \mathrm{g})$. The results of the sensitivity test were recorded as sensitive or resistant.

Standardized bacterial suspension for bacterial inoculation in antibiotic sensitivity test was prepared by choosing 4-5 isolated colonies with the same shape and size, and by adding them to $5 \mathrm{ml}$ of brain-heart infusion broth to form a homogenous suspension, allowing to incubate at $37^{\circ} \mathrm{C}$ until it is slightly visibly turbid (about $4 \mathrm{~h}$ ). The turbidity of the suspension was adjusted to the optical density of a 0.5 McFarland tube $(0.14-0.15 \mathrm{~nm})$. The plates were inspected for inhibition zones after $24 \mathrm{~h}$ of incubation. Sensitivity pattern interpretation was done using the specific chart according to the recommendation of the Clinical and Laboratory Standards Institute (CLSI) (Wayne 2017).

\section{Detection of fungal agents}

Two specimens of the material of lacrimal sac content were used for fungal detection. Wet preparation in $10 \%$ $\mathrm{KOH}$ was done using the first specimen. Inoculation of plain Sabouraud's dextrose agar medium (SDA) was done using the second specimen. The inoculated Sabouraud's dextrose agar plates were incubated at $27{ }^{\circ} \mathrm{C}$, examined daily, and discarded at 14 days if no growth was seen in order not to miss slow-growing fungi. True growth was detected on the streak lines of inoculation, and any growth outside that lines was considered contaminations. Fungal growth was identified microscopically by lactophenol cotton blue stain, grossly identified from above, by colony morphology, and by pigment production on reverse (Cheesbrough 2006).

Antifungal susceptibility tests for fungal isolates were done using disc diffusion method: voriconazole $(1 \mu \mathrm{g})$, fluconazole $(25 \mu \mathrm{g})$, itraconazole $(10 \mu \mathrm{g})$, ketoconazole $(50 \mu \mathrm{g})$ metronidazole $(50 \mu \mathrm{g})$, and amphotericin B $(20 \mu \mathrm{g})$. The results of susceptibility were recorded as sensitive or resistant.

\section{Results}

Samples were obtained from 25 adult patients with chronic dacryocystitis and sent to the microbiology laboratory for evaluation. Female predominance was noticed among dacryocystitis infections. The results of the aerobic and anaerobic (bacterial) cultures are presented in (Table 1). Of the 25 samples, 15 (60\%) yielded a positive culture for different types of bacterial pathogens and $10(40 \%)$ yielded no growth. Of the 15 positive culture samples, 12 (48\%) showed single bacterial isolate while 3 (12\%) had mixed two types of bacterial isolates. Single eye was infected in all patients. There were 18 total culture isolates (Table 2), with 12/18 (66.7\%) Gram-positive, 5/18 (27.7\%) Gram-negative isolates, and $1 / 18(5.5 \%)$ were fungal isolates. The most common organisms were Gram-positive bacteria. Nine samples were Gram-positive bacteria accounting for $80 \%$ of the 15 positive cultures samples and $36 \%$ of all the samples. Three of the 15 positive culture samples had two different Gram-positive bacterial isolates. By far, the most common bacterial isolates were coagulase-negative staphylococci CNS and Streptococcal pneumococci where each were recovered in $4(16 \%)$ of all the samples accounting for $22.2 \%$ of all the isolates. Staphylococcus aureus was isolated from 3 samples (12\%), and they represented $16.6 \%$ of the isolates. Gram-negative bacteria were isolated from 5 samples (20\%), and they represented $27.7 \%$ of the isolates. The majority of Gram-negative bacterial isolates were Klebsiella and Pseudomonas, each represented 16.6\% and 11\% of the isolates respectively. Fungal organisms (Candida) were detected in 1 (4\%) sample, which accounted for $5.5 \%$ of the isolates.

The highest antibiotic susceptibility of all Gram-positive and Gram-negative bacterial isolates from chronic dacryocystitis was to gatifloxacin and amikacin, both 15/ 17 and $88.8 \%$, while the lowest susceptibility was to cephalexin 9/17, (53\%). The majority of the Gram-positive organisms were sensitive to gatifloxacin (91.6\%) followed by amikacin (83.3\%), while the majority of the Gram-negative organisms were sensitive to amikacin $(100 \%)$ followed by gatifloxacin and cefotaxime (80\%) each.

\section{Discussion}

The lacrimal excretory system is connected with the conjunctiva and nasal mucosa via its mucous membrane lining sharing their colonies of normal bacterial flora. Obstruction of the nasolacrimal duct will lead to the

Table 1 The number and percentage of the eyes (specimens) with positive growth and no growth

\begin{tabular}{lll}
\hline Growth pattern & Total no. of eyes & Percentage \\
\hline Total no. of eyes (specimens) & 25 & 100 \\
Total no. of eyes (specimens) with negative cultures & 10 & 40 \\
Total no. of eyes (specimens) with positive cultures & 15 & 60 \\
Total no. of eyes (specimens) with one bacterial isolate & 12 & 48 \\
Total no. of eyes (specimens) with two bacterial isolates & 3 & 12 \\
Total no. of microbial isolates & 18 & 72 \\
\hline
\end{tabular}


Table 2 The number and percentage of bacterial isolates from dacryocystitis cases

\begin{tabular}{llllll}
\hline Name of the bacterial isolate recovered & $\begin{array}{l}\text { Number of } \\
\text { organisms }\end{array}$ & $\begin{array}{l}\text { \% of positive } \\
\text { cultures }(n=15)\end{array}$ & $\begin{array}{l}\text { \% of all organisms } \\
(n=18)\end{array}$ & $\begin{array}{l}\text { Total no. of } \\
\text { positive samples }\end{array}$ & $\begin{array}{l}\text { \% of all culture } \\
\text { samples }(n=25)\end{array}$ \\
\hline Total Gram-positive cocci: & 12 & 80 & 66.7 & 9 & 36 \\
Staphylococcus aureus & 3 & 20 & 16.6 & 3 & 12 \\
Coagulase-negative Staphylococci & 4 & 26.6 & 22.2 & 4 & 16 \\
Streptococcus pneumonia & 4 & 26.6 & 22.2 & 4 & 16 \\
Streptococcus viridans & 1 & 6.6 & 5.5 & 1 & 4 \\
Fungal organisms: Candida species & 1 & 6.6 & 27.7 & 5 & 4 \\
Total Gram-negative bacilli & 5 & 33.3 & 11 & 2 & 8 \\
Pseudomonas species & 2 & 13.3 & 16.6 & 3 & 12 \\
Klebsiella species & 3 & 20 & 100 & 25 & 72 \\
Total Gram-positive and Gram-negative & 18 & 120 & & 5
\end{tabular}

stagnation of tears, mucoid secretions, and desquamated cells. This constitutes a favorable condition for secondary bacterial infection (Bharathi et al. 2008).

Women are more commonly affected by primary nasolacrimal duct obstruction. This was also the case in this study. Women have smaller lower nasolacrimal fossa and middle nasolacrimal ducts as proved by measuring the bony nasolacrimal system; this may explain the higher incidence of dacryocystitis in women (Groessl et al. 1997).

The levels of overall culture positivity might be influenced by different techniques of sample collection. Hartikainen et al. (Hartikainen et al. 1997) had collected refluxed secretion through the lacrimal punctum, or by swabbing with a sterile broth-impregnated swab the lower conjunctival cul-de-sac, and reported positive cultures in $84 \%$ samples. High positive samples were also obtained by Das et al (Das et al. 2008a) and reported $90.9 \%$ of the cases were positive for bacteria, $74.5 \%$ had single isolations while $16.3 \%$ had mixed bacterial isolations. Also Chaudhry et al. (Chaudhry et al. 2005) reported that $97.3 \%$ were positive for bacteria, $33.9 \%$ of the cultures showed a single microorganism, while $>2$ microorganisms were reported in $66.1 \%$ of the cultures. On the contrary, De Angelis et al. (DeAngelis et al. 2001) analyzed the posterior lacrimal flap and found that only $41.7 \%$ of the samples were positive. In our work, external-DCR was done under general anesthesia, and material (lacrimal sac cultures) was obtained directly from the lacrimal sac content while making sac flap using sterile swabs. We had found positive growth in $15(60 \%)$ specimens. Twelve of them (80\%) showed single isolations while 3 of them (20\%) showed mixed bacterial isolations. Similar positive growth results were obtained by Assefa et al. (Assefa et al. 2015) (60.8\%), Kebede et al. (Kebede et al. 2010) (79.8\%), and more recently Chaudhary et al. (Chaudhary et al. 2010) (76.6\%). For positive culture, $85.86 \%$ showed a single isolates and $14.13 \%$ showed a mixed isolates.
In this study, as shown in Table 2, Gram-positive cocci were found in $66.7 \%$ of the isolates, and similarly Bharathi et al. (Bharathi et al. 2008), Mills et al. (Mills et al. 2007), and Hartikainen et al. (Hartikainen et al. 1997) reported $69.7 \%, 64.9 \%$, and $69.2 \%$ Gram-positive cocci from patients with dacryocystitis, respectively. Also in more recent study, Shahraki et al (Shahraki et al. 2016) showed that staphylococci and other Gram-positive have the most frequency in patient's eye pus. The most common organism isolated in our study was Staphylococcus species, accounting for $38.8 \%$ of the isolates. A similar incidence was reported by Das et al. (Das et al. 2008b), Huber-Spitzey et al. (Huber-Spitzy et al. 1992), and Coden et al. (Codon et al. 1993), their percentage being $75 \%, 51 \%$, and $49 \%$ respectively. Sun et al. (Sun et al. 2005) in a study of chronic dacryocystitis in China reported that Staphylococci accounted for $34.5 \%$ of isolates in their series.

Streptococcus pneumoniae represented $22 \%$ of the bacterial isolates in this study, which is higher than Huber-Spitzy et al. (2\%) Coden et al. (2.3\%), and Hartikainen et al. (5\%). This percentage compares fairly well with results of Bharathi et al. (10\%), Mandal et al. (10\%), Chaudhary et al. (19.8), and Kebede et al. (23\%).

Gram-negative organisms represented $27.7 \%$ of all isolates; the most common isolated species was Klebsiella species (16.6\%) followed by Pseudomonas species (12\%). Similarly, Coden et al. (Codon et al. 1993) observed Gram-negative organisms in $27 \%$ of all isolates, reporting Pseudomonas aeruginosa in $9 \%$ of the isolates. Huber-Spitzy et al. (Huber-Spitzy et al. 1992) reported Gram-negative organisms accounting for $26 \%$ of the isolates, the most frequent species being E. coli (12\%). Bharathi et al. (Bharathi et al. 2008) observed Gram-negative organisms in $29 \%$ of the isolates, the predominant isolated species being Pseudomonas species (10\%) followed by E. coli (4.7\%). Hartikainen et al. (Hartikainen et al. 1997) reported that Gram-negative organisms represented 17\% of 


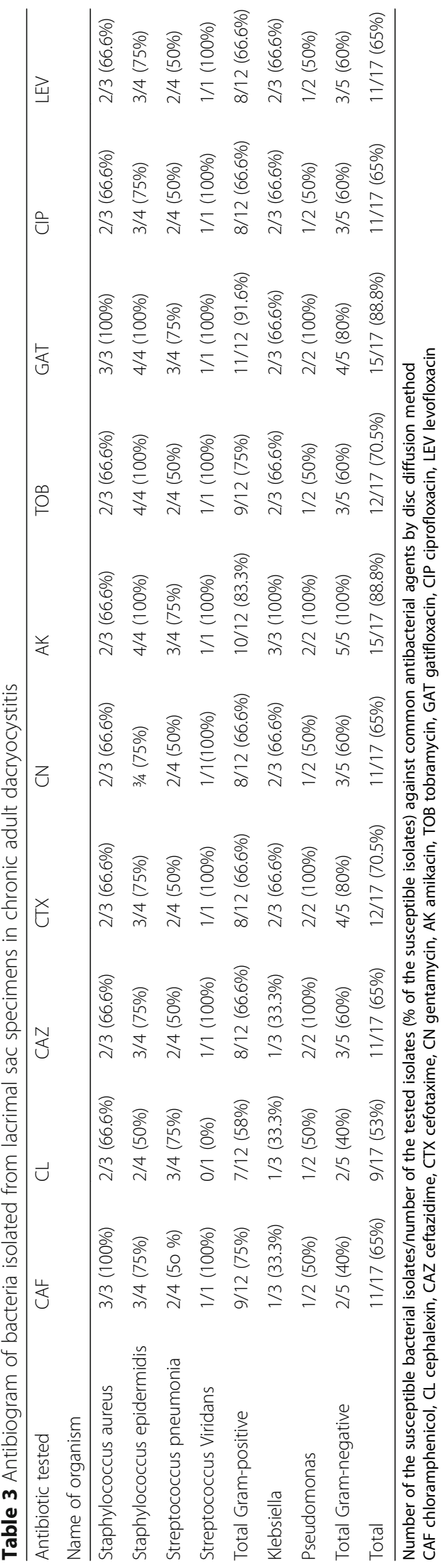


all the isolates, the most commonly isolated species being Haemophilus influenza (4\%). However, recently, Briscoe et al. (Briscoe et al. 2005) recovered $61 \%$ of the bacterial isolates as Gram-negative bacilli with the predominance of Pseudomonas aeruginosa (22\%) from pus samples of dacryocystitis.

In this study, fungal organisms were detected in 5.5\% of the positive cultures; the predominant fungus was Candida species. Brook and Fraiser (Brook and Frazier 1998) reported that fungal species constituted $5 \%$ of the isolates in their series.

The spectrum of aerobic and facultative organisms recovered in this study is also consistent with results, reported by Brook and Fraiser in the USA, as Staphylococcus, Pseudomonas, and Streptococcus species were also among the predominant pathogens.

The analysis of the antibiogram of bacterial isolates (Table 3) showed that among the cephalosporins, the first generation of cephalosporins, cephalexin (58\%), showed lower efficacy against Gram-positive isolates when compared with the third generation of cephalosporins, ceftazidime (66\%), and cefotaxime (66\%). Gram-negative isolates were also more sensitive to the cefotaxime (80\%) followed by ceftazidime (60\%) and cephalexin (40\%). Similarly, Briscoe et al. (Briscoe et al. 2005) reported that ceftazidime and cefuroxime (third generation of cephalosporins) showed sensitivity (95\%) and (50\%) respectively while cephalexin showed (14\%).

Among the aminoglycosides, amikacin showed higher effectiveness toward Gram-positive and Gram-negative isolates. Similarly, Sun et al. (Sun et al. 2005) observed higher effectiveness of amikacin for both Gram-positive and Gram-negative isolates. In a more recent study of the bacteria antibiotic resistance demonstrated the highest bacterial sensitivity to antibiotics was for chloramphenicol (76.7\%), gentamycin (66.7\%), and amikacin (60\%) (Shahraki et al. 2016).

Among the fluoroquinolones, the gatifloxacin showed increased efficacy against all pathogens more than ciprofloxacin and levofloxacin which showed lower efficacy against all pathogens. Similarly, Bharathi et al. (Bharathi et al. 2008) observed higher effectiveness of gatifloxacin against Gram-positive and Gram-negative bacterial isolates. In a study done by Lijuan et al. (Chen et al. 2018) in China, all Gram-positive bacteria showed sensitivity to vancomycin and $86.5 \%$ sensitive to gatifloxacin. Meanwhile, nearly all Gram-negative bacteria showed sensitivity to gatifloxacin (99.5\%), and $92 \%$ were sensitive to tobramycin and ceftazidime. Thus, gatifloxacin was the best choice agent against all Gram-positive, Gram-negative, and anaerobic isolates.

In our study, clinicobacteriological study of chronic dacryocystitis demonstrated the increased prevalence of Gram-negative organisms particularly Pseudomonas and
Klebsiella. These findings indicate that the antibiotic susceptibility test and treatment protocol before and after lacrimal surgery should be done.

The study of clinicobacteriological character of chronic purulent dacryocystitis done by Briscoe et al. (Briscoe et al. 2005) demonstrated a significant change in bacterial flora and antibiotic treatment. A higher isolation percentage of Gram-negative bacteria particularly Pseudomonas was detected and showed increasing resistance to the commonly used antibiotics. The emergence of rare highly resistant Gram-negative microorganisms may also indicate a new picture in lacrimal sac infections (Briscoe et al. 2005).

\section{Conclusion}

Clinicobacteriological study of chronic dacryocystitis in adults demonstrated predominance isolation of Grampositive Staphylococcal species, along with an increased incidence of Gram-negative organisms, Klebsiella pneumoniae and Pseudomonas species, which was not part of the conjunctival flora. On the contrary, Gram-negative bacteria are a threat of post-operative infection in ophthalmic and lacrimal drainage surgeries. For this reason, antibiotic prophylaxis in lacrimal drainage surgery should be effective against Gram-negative bacteria as well. We recommend that microbiological analysis, and culture and sensitivity test are mandatory to be done to all cases with microbial infection for the selection of the effective antimicrobial treatment and to help control the increasing rate of antibiotic resistance.

\section{Acknowledgements \\ Not applicable}

Funding

Not applicable

\section{Availability of data and materials}

All data generated or analyzed during this study are included in this published article.

\section{Authors' contributions}

SN made the main contributions to work design, microbiological laboratory testing of eye samples, data collection from patients' files, and other scientific data; helped in drafting the manuscript, and revising and approving the final version. She was responsible for the submission of the article as a corresponding author and resubmission after making the necessary revision and correction to the manuscript. AE has been involved in microbiological laboratory testing; microbial isolation and antibiotic sensitivity tests of the eye samples; and recording of results, data collection, drafting of the article, and revising and approving the manuscript content. TS performed the clinical work of the study including patient examination and diagnosis, obtaining samples intraoperative, supervised the immediate transport of samples to the microbiology laboratory, revised the manuscript, and gave final approval for publishing. MY shared performance of the clinical aspect of the work including patient's examination, and diagnosis and surgical interference, sample collection, and follow-up. He revised the draft of the clinical aspect of the study, read the manuscript, and gave his final approval to be published. OA shared patients' examination and diagnosis, supervised the sample transport, helped in the collection of scientific data, revised the manuscript, and gave her 
final approval to be published. All authors read and approved the final manuscript.

\section{Ethics approval and consent to participate}

Agreement for the study, in addition to the ethical approval was obtained first from the Medical Research Committee of RIO, Egypt. All the patients who were enrolled had submitted an informed consent in advance.

\section{Consent for publication}

Not applicable (participants were fully anonymous).

\section{Competing interests}

The authors declare that they have no competing interests.

\section{Publisher's Note}

Springer Nature remains neutral with regard to jurisdictional claims in published maps and institutional affiliations.

\section{Author details}

${ }^{1}$ Department of Microbiology and Parasitology, Research Institute of Ophthalmology, El Ahram Street, (RIO), Giza 12611, Egypt. ${ }^{2}$ Infection Control Unit, Department of Microbiology and Parasitology, RIO, Giza, Egypt.

${ }^{3}$ Ophthalmology, Oculoplastic Department, RIO, Giza, Egypt. ${ }^{4}$ Department of Ophthalmology, RIO, Giza, Egypt.

Received: 14 November 2018 Accepted: 13 February 2019

Published online: 26 February 2019

\section{References}

Assefa Y, Moges F, Endris M, Zereay B, Amare B, Bekele D et al (2015) Bacteriological profile and drug susceptibility patterns in dacryocystitis patients attending Gondar University Teaching Hospital, Northwest Ethiopia. BMC Ophthalmol 2:15-34 Available from: https://www.ncbi.nlm.nih.gov/pmc/ articles/PMC4396718/

Badhu BP, Karki BS, Khanal B, Dulal S, Das H (2006) Microbiological patterns of chronic dacryocystitis. Ophthalmology 113(12):2377.e1-2 Available from; https://www.ncbi.nlm.nih.gov/pubmed/17157151.

Bharathi MJ, Ramakrishnan R, Maneksha V, Shivakumar C, Nithya V, Mittal S (2008) Comparative bacteriology of acute and chronic dacryocystitis. Eye 22:953960 Epub 2007 Jun 29.

Briscoe D, Rubowitz A, Assia El (2005) Changing bacterial isolates and antibiotic sensitivities of purulent dacryocystits. Orbit 24(2):95-98.

Brook I, Frazier EH (1998) Aerobic and anaerobic microbiology of dacryocystitis. Am J Ophthalmol 125(4):552-520.

Chaudhary M, Bhattarai A, Adhikari SK, Bhatta DR (2010) Bacteriology and antimicrobial susceptibility of adult chronic dacryocystitis. Nepal J Ophthalmol 2(2):105-113 [PubMed].

Chaudhry IA, Shamsi FA, Al-Rashed W (2005) Bacteriology of chronic dacryocystitis in a tertiary eye care center. Ophthal Plast Reconstr Surg 21(3): 207-210.

Cheesbrough M (2006. Available from: https://www.medbox.org/districtlaboratory-practice-in-tropical-countries-part-2/preview. ISBN-13 978-0-51134842-6 eBook (EBL)) District Laboratory Practice in Tropical Countries. Part-2, Second edition UK. published in the United States of America by Cambridge University press, New York, pp 45-60.

Chen L, Fu T, Gu H, Jie Y, Sun Z, Jiang D et al (2018) Trends in dacryocystitis in China: a STROBE-compliant article. Medicine (Baltimore) 97(26):e11318 Available: from; https://eye.hms.harvard.edu/publications/trendsdacryocystitis-china-strobe-compliant-article.

Codon DJ, Hornblass A, Haas BD (1993) Clinical bacteriology of dacryocystitis in adults. Ophthalm Plast Reconstr Surg 9(2):125-131 Available from; https:// www.ncbi.nlm.nih.gov/pubmed/8323904

Das JK, Deka AC, Kuri GC, Bhattacharjee K, Das D, Gogoi K (2008a) Bacteriology of chronic dacryocystitis in adult population of northeast India. Orbit 27(4):243-247.

DeAngelis D, Hurwitz J, Mazzulli T (2001) The role of bacteriologic infection in the etiology of nasolacrimal duct obstruction. Can J Ophthalmol 36(3): 134-139.

Eslami F, Basir HR, Moradi A, Farah S (2018) Microbiological study of dacryocystitis in northwest of Iran. Clin Ophthalmol 12:1859-1864. https://doi.org/10.2147/ OPTH.S175463.
Groess SA, Sires BS, Lemke BN (1997) An anatomical basis for primary acquired nasolacrimal duct obstruction. Arch Ophthalmol 115(1):71-74.

Hartikainen J, Lehtonen OP, Saari KM (1997) Bacteriology of lacrimal duct obstruction in adults. Br J Ophthalmol 81(1):37-40.

Huber-Spitzy V, Steinkogler FJ, Huber E, Arocker-Mettinger E, Schiffbänker M (1992) Acquired dacryocystitis: microbiology and conservative therapy. Acta Ophthalmol (Copenh) 70(6):745-749. https://doi.org/10.1111/j.1755-3768. 1992.tb04880.x.

Hudzicki Jan: Kirby-Bauer disk diffusion susceptibility test protocol. American Society for Microbiology ASM, Microbe Library. Created December 2009, last update April 2013.

Kebede A, Adamu Y, Bejiga A (2010) Bacteriological study of dacryocystitis among patients attending in Menelik II Hospital, Addis Ababa, Ethiopia. Ethiop Med J 48(1):29-339.

Mandal R, Banerjee AR, Biswas MC, Mondal A, Kundu PK, Sasmal NK (2008) Clinicobacteriological study of chronic dacryocystitis in adults. J Indian Med Assoc 106(5):296-298.

Mills DM, Bodman MG, Meyer DR, Morton AD (2007) The microbiologic spectrum of dacryocystitis: a national study of acute versus chronic infection. Ophthal Plast Reconstr Surg 23(4):302-306.

Shahraki K, Makateb A, Shirzadi K, Khosravifard K (2016) Frequency of bacterial samples from patients with chronic acquired nasolacrimal duct obstruction. Med Arch 70(6):433-436.

Sun X, Liang Q, Luo S, Wang Z, Li R, Jin X (2005) Microbiological analysis of chronic dacryocystitis. Ophthalmic Physiol Opt 25(3):261-263.

Wayne, PA: 2017 Performance standards for antimicrobial susceptibility testing. 27th ed. clinical laboratory standard institute supplement M100. https://clsi.org/ media/1469/m100s27_sample.pdf.

\section{Submit your manuscript to a SpringerOpen ${ }^{\circ}$ journal and benefit from:}

- Convenient online submission

- Rigorous peer review

- Open access: articles freely available online

High visibility within the field

- Retaining the copyright to your article

Submit your next manuscript at $\boldsymbol{\nabla}$ springeropen.com 